\title{
Issues of Surrogacy in India
}

\author{
Suketu V. Shah
}

\begin{abstract}
A surrogacy arrangement or surrogacy agreement is the carrying of a pregnancy for intended parents. There are two main types of surrogacy, Gestational surrogacy and Traditional surrogacy.

This research encompasses with these problems which concerned about the issue of surrogacy and rights of women. It furthermore explains about different issues of surrogacy. This paper also laid about Legal issues, Psychological issues, Religious issues, Ethical issues, General issues and Health issues. This paper shows about different types of surrogacy. Though, this paper also focuses on the rights of surrogate mother and child and initiative taken by the government for the enhancement of the surrogacy and their rights in India. In this research I conceptualize the incidents related to the surrogacy and the legal issues in the global scenario, however, I also gestate the landscape of surrogacy in India, as it is a new concept for India and not acceptable as well on various portfolios so I also laid focus on the social and economic background for the profound this concept in the grass root level. While construing this research $I$ also analyze the Artificial Reproductive Technology (ART) Bill, in that I critically analyze it's positive and negative aspects for the research also laid impact over commissioning parents and their rights regarding surrogacy. In the conclusion my research concludes procreating a child in surrogate woman womb is grateful gift to those mothers who cannot conceive child.
\end{abstract}

Index Terms - Gestational surrogacy, issue, intended parents, surrogate mother, traditional surrogacy.

\section{INTRODUCTION}

A surrogacy arrangement or surrogacy agreement is the carrying of a pregnancy for intended parents. There are two main types of surrogacy, gestational surrogacy and traditional surrogacy.[1] In gestational surrogacy, the pregnancy results from the transfer of an embryo created by in vitro fertilization (IVF), in a manner so the resulting child is genetically unrelated to the surrogate.[2] Gestational surrogates are also referred to as gestational carriers. In traditional surrogacy, the surrogate is impregnated naturally or artificially, but the resulting child is genetically related to the surrogate. In the India, gestational surrogacy is more common than traditional surrogacy and is considered less legally complex.

Intended parents may seek a surrogacy arrangement when either pregnancy is medically impossible, pregnancy risks present an unacceptable danger to the mother's health or is a same sex couples preferred method of procreation. Monetary compensation may or may not be involved in these arrangements. If the surrogate receives compensation beyond reimbursement of medical and other reasonable expenses, the

Manuscript received August 12, 2016; revised October 12, 2016.

Suketu V. Shah is with the Saurashtra University, Rajkot, Gujarat State, India (e-mail: sukvencom94@gmail.com). arrangement is considered commercial surrogacy; otherwise, it is referred to as altruistic. The legality and costs of surrogacy vary widely between jurisdictions, sometimes resulting in interstate or international surrogacy arrangements.

\section{Gestational Surrogacy}

The Gestational Surrogacy using Intended Parent Eggs program is designed for intended parents who have the ability to provide all of the needed biology to create embryos but require the assistance of a gestational surrogate. [3] Circle staff assists you in the selection of an IVF center if you are not already established with a medical team. You are then matched with a gestational surrogate that meets your legal, psychological and emotional needs.

\section{I.V.F. — TREATMENT OPTION}

This method is used in the following cases:

1) Abnormal semen analysis findings i.e. low sperm concentration or a high level of abnormal sperm with low motility.

2) Concept of surrogacy in India. Eventually, this research also laid impact over negative aspects of surrogacy in India. Eventually, this Fertilization using sperm surgically extracted from testicles or the epididymis.

3) Failure to spontaneously fertilize in the previous cycle even though semen analysis results are positive.

4) ICSI technique improves pregnancy rates and reduces the number of IVF miscarriages.[4]

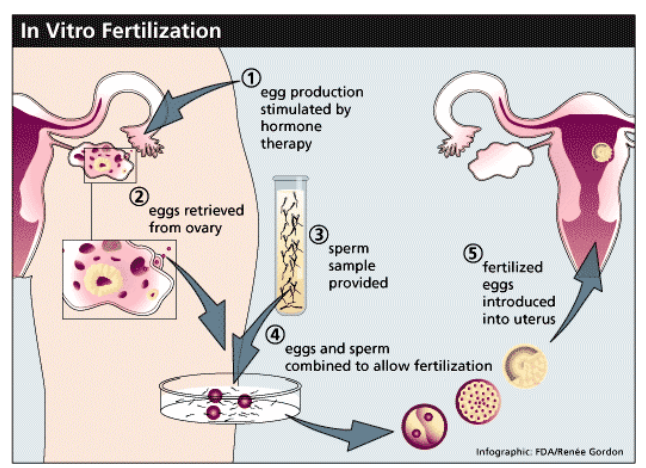

Fig. 1. Intra cytoplasmic sperm injection.

\section{SOCIO-PSYCHOLOGICAL ISSUES}

Research has focused on a number of specific issues: attachment and disclosure to surrogate offspring; experiences, characteristics and motivations of surrogate mothers; and changes in profiles of the commissioning/intended mothers. 
Women giving up babies still fall outside the acceptable remit. Normal population surveys, on the contrary, are less accepting of third party reproduction; they have no personal need to reconsider and hence maintain their original normative cognitively consonant state. Psychological issues involved in surrogate motherhood triads:

- The Surrogate Mother (or Couple) Relinquishing the Baby at or Soon after Birth.

- The commissioning or intended mother (or couple) receiving the commissioned Baby and The offspring [5].

In Ciccarelli's (1997) research more than half of the participants experienced conflict in interpersonal relationships as the result of being a surrogate mother and over $40 \%$ mentioned having lost a relationship as a result. Most are general side effects of pregnancy that involve physical discomfort, experienced by all birth mothers. Women who become surrogate mothers usually have good reason to believe they will have normal, relatively easy pregnancies, but all experience routine aches and pains and some experience complications that may lead to a difficult pregnancy. In surrogacy, the father feels discomfort and awkwardness that a woman other than his wife is the mother of the child. From the child's perspective, the mechanisms of how a pregnancy was achieved would be a minimal psychological issue compared to whether one's birth mother chose not to keep the child. Researchers Fazli Khalaf, Abdollah Shafiabadi and Madjid Tarahomi report in "The Journal of Reproduction and Infertility" that giving the child up may be extremely distressing to the mother and may even result in psychological problems. [6] Surrogate motherhood can cause conflicts in the family, as well as strained relationships between the surrogate mother and her husband. He may struggle to accept the fact that his wife is pregnant with a child unrelated to either of them, and the children in the family may wonder why they are not going to have a new sibling. Some surrogates are very young and may not understand the consequences and regret their decisions later at the time of relinquishment or even later in life, when it is too late to do anything about it. In India surrogates explicitly stated that money was one reason for becoming a surrogate. Surrogate mothers expected their commissioning parents to be open about the child's origins, as they themselves had told all their own children about the surrogate baby being part of the intended couple's family-not their own. As a result of this, most surrogate mothers expected some contact between them to continue following relinquishment of the baby, so that they maintained their new friendships and their children could still see the surrogate child. During the nine months of gestation, the biological mother bonds with and becomes emotionally attached to the baby growing inside her. Earlier studies checking the outcome of children in lesbian families included women who had become mothers in the context of a heterosexual marriage before adopting a lesbian identity and who were compared with single heterosexual mothers. No differences between their children were identified for emotional-well being, quality of friendships or self- esteem, or in terms of masculinity or femininity. Regarding the parenting ability of the mothers themselves, it was demonstrated that lesbian mothers were just as child-oriented, just as warm and responsive to their children and just as nurturing and confident as heterosexual mothers. [7]

\section{LEGAL ISSUES}

The Indian system only recognizes the birth mother. There is no concept of DNA testing for establishing paternity as far as the Indian legal system is concerned, i.e., the name on the child's birth certificate has to be that of the birth mother and her husband. In 2008 the Supreme Court of India in the Manji's case (Japanese Baby) has held that commercial surrogacy is permitted in India and it has again increased the international confidence in going for surrogacy in India.

The 35-page bill seeks to regulate India's heavily market-driven fertility industry, and introduces a number of policies ranging from clinic regulation to restrictions on ART access. Some points that are worth noticeable in Indian Surrogacy Bill, which the bill formally includes, are:

1) Surrogacy shall not be available to "patients for whom it would normally be possible to carry a baby to term."

2) Surrogacy contracts shall be legally enforceable.

3) Married women need their husband's consent in order to become a surrogate.

4) Surrogates shall not undergo embryo transfer more than three times for the same couple.

5) Egg donor identities shall remain strictly confidential.

6) There shall be a detailed accreditation process for fertility clinics and gamete donor banks.

7) The Department of Health Research shall establish and manage a "national ART registry."

8) The only "couples" eligible for ART shall be those "having a sexual relationship that is legal in India." (This would apparently exclude gay couples.)

9) Foreigners seeking surrogacy services must provide written proof that their home country "permits surrogacy, and the child born through surrogacy in India, will be permitted entry in the country." (This would apparently exclude people from Canada and a number of European countries that specifically prohibit commercial surrogacy, and could exclude people from countries that don't explicitly permit it.)

10) The bill also calls for the formation of both national and state advisory boards composed of Health Department workers, industry representatives, scientists, and other civil society members. These boards are charged with operational zing and enforcing the many guidelines enumerated in the bill.

11) The ICMR's ART Bill, 2010, has put in place several important provisions. It says a woman acting as a surrogate mother in India cannot be less than 21 years or over 35 years. Also, she cannot give more than five live births, including her own children.

12) The Bill mandates the appointment of a local guardian in case of surrogacy arrangements where the intended couple is staying outside India. This local guardian will be legally obliged to take delivery of the child born of the surrogacy arrangement if the intended couple does not do so.[8]

13) Bill introduced by an individual member of parliament and is not government sponsored bill. 
14) This Bill deals on with surrogacy arrangements alone and not with Assisted Reproductive Technology as such.

15) The Bill provides to allow commercial surrogacy arrangements for couples from abroad if they have an appointed guardian in India.

16) Bill does not discuss ART Banks, whereby surrogate mother and egg donors can be identified.

17) Bill provides for insurance for surrogate mother must be sponsored by the commissioning couple.

18) Bill provides for surrogacy for gay couples, after same sex relations are allowed in India.

\section{HEALTH ISSUES}

All women considering surrogacy should be aware that there are serious risks with IVF, fertility medications, pregnancy and childbirth. The list compiled below is an extensive list of all types of side effects, complications and serious risks that surrogate mothers face. Common side effects during pregnancy like exhaustion (weariness common from first weeks), altered appetite and senses of taste and smell, nausea and vomiting $(50 \%$ of women, first trimester), heartburn and indigestion, constipation, weight gain, dizziness and light-headedness, bloating, swelling, fluid retention, hemorrhoids.[9] The concept of surrogacy in India is not new. Commercial surrogacy or "Womb for rent," is a growing business in India. In India, English speaking environment and cheaper services attract the willing clients. Future projections of surrogacy practice range from opportunity to exploitation - from rural women in India uplifted out of poverty to a futuristic nightmare of developing country baby farm. In case of surrogacy in India, it is hard to tell that whether these women are exercising their own personal rights or whether they are forced to become surrogate mothers due to their mother-in-law's or husband's desire to fulfill material and financial needs.

Opponents of surrogacy argue that the practice is equivalent to prostitution and by virtue of that similarity; it should be disallowed on moral grounds. Surrogacy contracts are "dehumanizing and alienating " since they deny the legitimacy of the surrogate's perspective on her pregnancy. Surrogate mother tries to avoid developing a special bond with the child in her and views the pregnancy as merely a way to earn the much-needed money. The payment for bodily services dehumanizes the surrogate mother and exploits her reproductive organs and capability for personal gains of the wealthy.

\section{ReLigious ISSUES}

Surrogacy is a complex and contentious moral and ethical issue across global cultures. Religions naturally have views on procreation, because the spiritual laws guiding human life are their domain. Religious views on surrogacy vary from complete prohibition to acceptance. The rise of Westerners using Indian surrogate mothers has added a political dimension to the religious and legal debate. Religions naturally have views on procreation, because the spiritual laws guiding human life are their domain. The Christian religion Bible has also been interpreted as stating that children are a gift, not a right. [10] God chooses whether people have babies or not; if a couple is childless, it may be God's will. When individuals or couples are unable to naturally bear children, they have several other alternatives in starting a family. Certainly, while adoption is one choice, there are many who wish to see a child through conception, pregnancy, birth, and rearing. For some, there is also the issue of having a true biological connection with that child.

Muslim religion believe that all kinds of the surrogacy arrangements are Haram in the Muslim Tradition and the rules and regulation of the surrogacy arrangements involved in the surrogacy arrangements.[11] Gestational surrogacy as a treatment for infertility is being practiced in some well-known medical institutions in Tehran and some other cities in Iran. While the majority of Muslims in the world are Sunni, the majority of Iranians are Shiite. Most Sunni scholars do not permit surrogate motherhood, since it involves introducing the sperm of a man into the uterus of a woman to whom he is not married. Most Shiite scholars, however, have issued jurisprudential decrees (fatwas) that allow surrogate motherhood as a treatment for infertility, albeit only for legal couples. They regard this practice as transferring an embryo or fetus from one womb to another, which is not forbidden in Shiite jurisprudence. Nevertheless, there are some controversies concerning some issues such as kinship and inheritance. [12] The main ethical concern of Iran's experience with gestational surrogacy is the monetary relation between the intended couple and the surrogate mother. While monetary remuneration is practiced in Iran and allowed by religious authorities, it seems to suffer from ethical problems. This article proposes that this kind of monetary relation should be modified and limited to reimbursement of normal costs. Such modification requires new legislation and religious decrees. All kind of the surrogacy arrangements are Haram in the Muslim Tradition and the rules and regulation of the surrogacy arrangements involved in the surrogacy arrangements.

Jewish law permits surrogacy only if it is a full gestational surrogacy. Also, the gametes of both intended parents should be included and in vitro fertilization should be the mode of fertilization followed.

Despite the different issues pertaining to surrogacy, statistics reveal that there has been a steady rise in the number of women donning the role of surrogates. In 2006 alone, the Society for Assisted Reproductive Technology or SART estimated about 260 surrogate deliveries, and since then the number has been on a constant rise.

\section{Situational ANALYSIS}

My survey is done on situational Analysis Response. For better understanding the process I have conducted a situational Analysis. The situational analysis was conducted in 25 surrogate mothers across three blocks; Kheda, Anand, Ahmedabad were selected randomly. I find that majority of the surrogate mothers were between the age of 25 and 35. In age group 25 to 30 the $44 \%$ of the surrogate mothers fell in the 31-35 years age-group categories it is $40 \%$ and $16 \%$ of them came from more than 35 years age group categories. 
Almost all the surrogate women belonged to Hindu religion $52 \%$ and also $48 \%$ belongs to Christianity. All the surrogate mothers belonged to male- headed household. This fact to a great extent reveals that woman becomes a surrogate mother with her husband's approval in order to support the family income. Due to the nuclear family structure, majority of the households are comprised of few family members $68 \%$ surrogates comes due to get money for children education. The same percentage surrogate's means $68 \%$ come to this contract due to building a new home for family. Some other reason like debt payment for house is $28 \%$ the same percentage $28 \%$ for debt payment of land. These mothers do surrogacy for different motto like Different motto like for new home, for money, for child education, for debt payment, Repairing home, to get auto to join in surrogacy process. They discussed the plan to become surrogacy with their family members, husband, friends, agents, in laws etc. Initially some of them husbands are deny joining the surrogacy process but after counseling with agent or some other friends they agreed to do so. This mother majority never want to tell their children about the surrogacy. Few says their husband say about in future and few says if their child will ask in future then only they will say otherwise no. some mothers' parents are not supportive initially in this process. The occupations of surrogate mother at the time of joining surrogacy shows among the survey $76 \%$ surrogates are house wife and not doing any job or business at the time of joining the surrogacy, $8 \%$ are among them health worker and doing primary level job as health worker at small hospitals. Some of them are as labor worker and among them $16 \%$ are doing work as daily wages. The educational background of surrogate mother majority of them are means $40 \%$ are having primary education among them $20 \%$ are high school and $12 \%$ are having secondary education. $28 \%$ mothers are uneducated. Almost half of the respondents were educated to primary. However, around $28 \%$ of the surrogate mothers are illiterate, which is an important observation as it affects their ability to be involved in gainful employment either in the public or private sector. My finding shows that the surrogate spouse is having $8 \%$ without occupation means no service or job or labor. Among the respondents $28 \%$ are only daily wages and more spouses are having job or service. Only $64 \%$ surrogate mothers are covered for their health insurance. And most of the part $36 \%$ mothers are not covered health insurance. Same as in a mother is going for second surrogacy $40 \%$ is only covered the health and medical insurance while $60 \%$ mother is not covered the health or medical insurance. It is found that no maternity covered in this insurance so it is life insurance and not medical insurance. Doctor suggests life insurance against death benefit. average surrogate mothers get between Rs. 2000 to 3000 during surrogacy process monthly $40 \%$ of mothers are getting 3000 Rs. among them $8 \%$ are getting Rs 2500 per month as monthly expense and more mothers $52 \%$ are getting Rs.2000 per month as monthly expense. It is noted that the mothers have to stay at surrogate hostel up to 9 months and all the expenses are covered by the agency or doctor. The mother who get maximum amount per year as pocket money as 4 number of respondents gets 1, 20,000 Rs. per year as around $16 \%$ of the total respondents. $48 \%$ gets Rs.1, 30,000 as yearly expenses, $12 \%$ gets Rs. 1, 40,000 and rest $24 \%$ gets Rs. 1, 50,000 as yearly expenses for pocket money. The mother having natural children sex male is $70.21 \%$ and female birth is $29.78 \%$. It is also noted that during their natural pregnancy she is having more male child. The type of pregnancy is shown that $100 \%$ mother are natural pregnancy type no one is having Caesar at their natural pregnancy. Comparing with it to surrogacy process only $59.45 \%$ are having male child and $40.54 \%$ are Female child. But the information shows $100 \%$ Caesar has been done during surrogacy process while not a single means $0 \%$ is normal delivery. It is noted that after surrogacy the $100 \%$ mother are going for C- section by Caesar operation. Also during the surrogacy process the mother have different side effects like stretch marks (worse in younger women), loose skin, permanent weight gain or redistribution, abdominal and vaginal muscle weakness, pelvic floor disorder (occurring in as many as 35\% of middle-aged former child-bearers and $50 \%$ of elderly former child-bearers, associated with urinary and rectal incontinence, discomfort and reduced quality of life), changes to breasts, varicose veins ,scarring from episiotomy or c-section.

These mothers are have some permanent side effect like stretch marks (worse in younger women) loose skin, permanent weight gain or redistribution, abdominal and vaginal muscle weakness, pelvic floor disorder (occurring in as many as $35 \%$ of middle-aged former child-bearers and $50 \%$ of elderly former child-bearers, associated with urinary and rectal incontinence, discomfort and reduced quality of life), changes to breasts, varicose veins

It is reported that about $24 \%$ of the mothers who are in surrogacy process are having permanent complications like hysterectomy (removal of uterus), salpingectomy (removal of fallopian tube), and future infertility.

\section{CONCLUSION}

From Scripture several things seem clear. There are certain recommendations are provided for the surrogacy in India.

There should be legislation directly on the subject of surrogacy arrangement involving all the two parties i.e. the surrogate mother, the commissioning parents.

There should be a substantial regulation designed to protect the interests of the child.

Legal recognition of termination and transfer of parenting rights.

The surrogate mother should be provided by the copy of the contract as she is a party in the agreement and her interests should be taken into account. It is crucially important to maintain and monitor the anonymity of the surrogate mothers.

The surrogate mothers generally are from poor families and their average monthly income is not more than Rs. 2,500-6,000.

Almost all of the interviewed surrogate mothers have already experienced child-birth before and have two kids of their own. In such a way, this implies that these women are capable of reproduction naturally and are made subjects of reproductive assistance techniques and become surrogate 
mothers.

The majority of them are illiterate, employed as domestic helpers, construction workers or health workers. Thus, they are economically vulnerable and desire for some money. Hence, the need of money is the driving force for them to become surrogate mothers.

Most of the surrogate mothers are married and live in nuclear family structure, which makes the surrogacy decision-making easier for the couple.

The majority of them spend the money for education of their children, building the house or renovating the old one. Most of them stay in rented houses, which are kutcha or semi-pucca with poor or no latrine facilities. In some cases there was no roof over their houses due to which their children suffered from fever in rainy season.

Sometimes though the husbands do not mind the woman to go for surrogacy but after the baby is born and handed over and the woman comes back to her house, the husband and her own children distance themselves from her.

Most of the times it is the agent who approaches the particular woman for surrogacy to help her get in touch with the concerned clinic. These agents are often former surrogate mothers who have delivered two surrogate babies in the same clinic.

The surrogacy contract is signed between the surrogate mother (including her husband), the commissioning parents and the fertility physicians. In such a way, the clinic authorities evade legal hassles.

Almost none of the surrogate mothers have a copy of the written contract of surrogacy arrangement, though they are part of this contract.

\section{APPENDIX}

\author{
A.R.T. - Artificial Reproductive Technology \\ I.V.F. - In Vitro Fertilization \\ I.C.M.R. - Indian Council for Medical Research \\ I.C.S.I. - Intra Cytoplasmic Sperm Injection
}

\section{REFERENCES}

[1] M. Cooper, K. Vafadari, and M. Heida, Current Issues and Immerging Trends in Medical Tourism, $1^{\text {st }}$ ed. IGI Global, USA, 2015, ch.10, p. 139.

[2] L. Carangelo, The Adoption and Donor Conception Fact book, $1^{\text {st }}$ ed. , Access Press, California, ch.3, p. 147, 2015.

[3] C. Surrogacy, LTD. (August 2016). Parents, available programs for intended parents. Gestatetional Surrogacy. [Online]. Available: http://www.circlesurrogacy.com/parents/programs.

[4] Pragu Fertility Center. (August 2016). ICSI - Intracytoplasmic Sperm Injection. [Online]. Available: http://www.pragueivf.com/en/art/icsi/
[5] O. B. A. V. D. Akker. (July 7, 2006). Psychosocial aspects of surrogate motherhood. Oxford Journals Medicine and Health Update. [Online] Available: http://humupd.oxfordjournals.org/content/13/1/53.full

[6] D. Puzzo and B. P. Psicoterapia. (2016). Surrogate Mother, Psychological Aspects. [Online] Available: http://www.psicologi-rimini.it/?IDC=2\&ID=135

[7] A. Abbey, L. J. Halman, and F.M. Andrews, "Psychosocial, treatment and demographic predictors of the stress associated with infertility," vol. 57, pp. 122-128, 1992.

[8] A. Aberg and F. Mitelman. Surrogacy, Mumbai Indian surrogates, Rent-a-womb, Outsourcing Surrogacy in India, Surrogacy bills in India. (2015). [Online]. Available: https://surrogacymumbai.wordpress.com/surrogacy-bill-india/

[9] Surrogacy in Canada online articles, Risks to Surrogate Mothers (2001-2016). [Online]. Available: https://surrogacy.ca/resources/articles/53-risks-to-surrogate-mothers.h tml

[10] Modern Family surrogacy Center, Christian Surrogacy. (2016). [Online].

Available: http://www.modernfamilysurrogacy.com/page/christian_surrogacy

[11] Shodhganga, Ch5, Objectives and Hypothesis of Research Problem. [Online].

Available: http://shodhganga.inflibnet.ac.in:8080/jspi/bitstream/10603/43044/15/ 15_chapter\%20no\%205.pdf

[12] K. Aramesh, "Surrogacy is prohibited in Islam, medical ethics and history of medicine research center," Journal of Medical Ethics, vol. 35, no. 5, 2009.

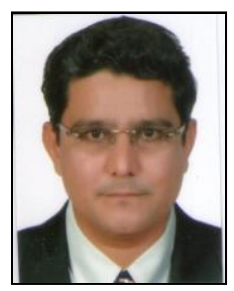

Suketu V. Shah. was born in Nadiad, India in 1975 He has completed his bachelor degree in chemica engineering from Gujarat University, India, 1999. He has also completed his diploma in chemical engineering, TEB, Gujarat state, India, 1996. He has completed his LL.B. (bachelor of laws) from Gujarat University, India, 2009 and $\mathrm{He}$ also completed his LL.M. (master of laws) from Gujarat University, India, 2011. He is currently doing Ph.D. in law at Saurashtra University, Gujarat, India on the subject” Issue of Surrogacy- Challenged and Results".

He is a research scholar at the Department of Law, Saurashtra University, Gujarat, India. He works as a guest lecturer at M.S. Bhagat \& C.S. Sonawala Law college, Nadiad, Gujarat, India since 2011. Presently working as a supervisor instructor for A.O.C.P. Trade in Chemical group at Directorate of Employment \& Training, Government of Gujarat, India since 2001. He worked as Shift In charge at Amoli organics Ltd, India in 2000-2001. He also worked at Marigold Paints as Shift In charge in 1999-2000. He has presented paper in Research Matrix, International Multidisciplinary Journal of Applied Research as a research scholar on - "Issue of surrogacy- Challenges and Results" (ISSN: 2321-7073), 2016. He has also presented his paper on "Enhance Skill Development for Make in India by National Policy on Skill Development" at National Seminar on "Modern Education System:Multidisciplinary Perspective" organized by CTE Gujarat and MS University, Vadodara, India 2016. He presented paper on "Issue of surrogacy" at National Seminar on "Women Empowerment in India in 21st Century-A journey Begin” at SP University, India, 2016.

Mr. Suketu V. Shah is member of Bar council of Gujarat, India since 2011 and alumnus of M.S. Bhagat and C.S. Sonawala Law college, Nadiad, Gujarat, India. 